\title{
Feasibility of Revision Cochlear Implant Surgery for Better Speech Comprehension
}

\author{
Kyurin Hwang ${ }^{1}$, Jae Yong Lee ${ }^{1}$, Hyeon Seok Oh${ }^{1}$, \\ Byung Don Lee ${ }^{1}$, Jinsei Jung ${ }^{2}$, and Jae Young Choi ${ }^{2}$ \\ ${ }^{1}$ Department of Otorhinolaryngology-Head and Neck Surgery, Soonchunhyang University College of Medicine, Seoul, Korea \\ ${ }^{2}$ Department of Otorhinolaryngology-Head and Neck Surgery, Yonsei University College of Medicine, Seoul, Korea
}

Received September 21, 2018

Revised October 24, 2018

Accepted November 22, 2018
Background and Objectives: The purpose of this study was to evaluate the efficacy of revision cochlear implant $(\mathrm{Cl})$ surgery for better speech comprehension targeting patients with low satisfaction after first $\mathrm{Cl}$ surgery. Subjects and Methods: Eight patients who could not upgrade speech processors because of an too early $\mathrm{Cl}$ model and who wanted to change the whole system were included. After revision $\mathrm{Cl}$ surgery, we compared speech comprehension before and after revision $\mathrm{Cl}$ surgery. Categoies of Auditory Performance (CAP) score, vowel and consonant confusion test, Ling 6 sounds, word and sentence identification test were done. Results: The interval between surgeries ranged from eight years to 19 years Same manufacturer's latest product was used for revision surgery in six cases of eight cases. Full insertion of electrode was possible in most of cases (seven of eight). CAP score ( $p$-value $=0.01)$, vowel confusion test $(p$-value $=0.041)$, one syllable word identification test $(p$-val$\mathrm{ue}=0.026)$, two syllable identification test $(p$-value $=0.028)$, sentence identification test $(p$ value $=0.028$ ) had significant improvement. Consonant confusion test ( $p$-value $=0.063)$, Ling 6 sound test $(p$-value $=0.066)$ had improvement but it is not significant. Conclusions: Although there are some limitations of our study design, we could identify the effect of revision (upgrade) $\mathrm{Cl}$ surgery indirectly. So we concluded that if patient complain low functional gain or low satisfaction after first $\mathrm{Cl}$ surgery, revision (device upgrade) $\mathrm{Cl}$ surgery is meaningful even if there is no device failure.

J Audiol Otol 2019;23(2):112-117

\section{Introduction}

After development of a cochlear implant (CI) system, many hearing loss patients have relied on their $\mathrm{CI}$ system for better hearing life. Indication of $\mathrm{CI}$ have been enlarged compared to the early days, so the number of CI recipients are increasing. Because of that the cases of CI surgeries have been rising, the number of revision surgeries and the frequency of complications have been increasing too. Since HochmairDesoyer and Burian [1] first reported in 1985 that it is viable to remove and replace electrodes from within the cochlear, many authors have reported favorable results with revision CI sur-

This is an Open Access article distributed under the terms of the Creative Commons Attribution Non-Commercial License (https://creativecommons.org/licenses/by-nc/4.0/) which permits unrestricted non-commercial use, distribution, and reproduction in any medium, provided the original work is properly cited. geries in adults and children [2-10]. After first CI surgery in the past, there have been many advancements in implant and speech processor technology due to evolving biomedical technology and engineering. Speech comprehension and subjective satisfaction levels of CI recipients have improved and it seems to be better than for CI recipients in the early days. We advocate revision surgery for only device failures or medical reasons, not because of further improvement of speech comprehension. But most studies about revision surgery were about revision surgery for device failures or medical reasons and some of studies only discussed speech processor upgrade. So we evaluated efficacy of revision CI surgery for only better speech comprehension, targeting patients with low satisfaction after first CI surgery. 


\section{Subjects and Methods}

Between 1989 and January 2015, a total of 1,045 severe sensorineural hearing loss patients had CI surgery. We reviewed medical records retrospectively. Eight of them (six males and two females) who could not upgrade speech processors because of an early CI model and who wanted to change the whole system, had revision CI surgery. Table 1 provides a summary of general information for enrolled patients. Reasons for determination of revision surgery were various. All patients had low satisfaction in their CI system for a variety of reasons. So they wanted to change their whole implant system. All included patients had no medical problems or surgical complications.

At initial CI surgery, we used three CI22M implant and Spectra speech processor system and one CI24M implant and ESPrit22 speech processor system (Cochlear Ltd., NSW, Australia) and four Clarion $\mathrm{C} 1$ and PSP speech processor system
(Advanced Bionics, Valencia, CA, USA). In revision surgery, we used five Cochlear Ltd. CI system, two Advanced Bionics CI system and one MED-EL (Innsbruck, Austria) CI system. Table 2 shows detailed information about the implanted CI system.

We checked Categories of Auditory Performance (CAP) score, vowel and consonant distinction, Ling 6 sounds and word and sentence verification for evaluating speech comprehension in auditory only situation. Changes in speech comprehension score were evaluated using a Wilcoxon signed rank test using SPSS Statistics 21 software (IBM Corp., Armonk, NY, USA).

The authors had no ethical concerns in performing this retrospective study. This study was approved by the Institutional Review Board of Yonsei University (4-2017-0409) and informed consent was waived.

Table 1. General information for subjects

\begin{tabular}{|c|c|c|c|c|c|c|}
\hline $\begin{array}{l}\text { Patient } \\
\text { No. }\end{array}$ & $\begin{array}{l}\text { Gender/Age } \\
\text { (years) }\end{array}$ & $\begin{array}{l}\text { Pre lingual/ } \\
\text { Post lingual }\end{array}$ & $\begin{array}{l}\text { lst OP } \\
\text { date }\end{array}$ & $\begin{array}{l}\text { 2nd OP } \\
\text { date }\end{array}$ & $\begin{array}{l}\text { F/U period } \\
\text { (years) }\end{array}$ & Reasons for revision $\mathrm{Cl}$ surgery \\
\hline 1 & $M / 66$ & Post & 1989 & 2014 & 15 & Fail to adaptation, Low speech comprehension \\
\hline 2 & $M / 54$ & Post & 1992 & 2011 & 19 & $\begin{array}{l}\text { System failure, Impossible to aftercare services and speech } \\
\text { processor upgrade }\end{array}$ \\
\hline 3 & $\mathrm{~F} / 43$ & Post & 1996 & 2014 & 18 & $\begin{array}{l}\text { Speech processor breakdown, Production suspension } \\
\text { of previous SP model }\end{array}$ \\
\hline 4 & $F / 38$ & Pre & 2000 & 2011 & 11 & $\begin{array}{l}\text { Frequent SP breakdown, Patient wanted to change whole } \\
\text { system }\end{array}$ \\
\hline 5 & $M / 15$ & Pre & 2002 & 2015 & 13 & $\begin{array}{l}\text { Low speech comprehension, Patient wanted to change } \\
\text { whole system }\end{array}$ \\
\hline 6 & $M / 14$ & Pre & 2002 & 2012 & 10 & $\begin{array}{l}\text { Low speech comprehension, Patient wanted to change } \\
\text { whole system }\end{array}$ \\
\hline 7 & $M / 14$ & Pre & 2002 & 2012 & 9 & $\begin{array}{l}\text { Frequent SP breakdown, Patient wanted to change whole } \\
\text { system }\end{array}$ \\
\hline 8 & $M / 15$ & Pre & 2002 & 2010 & 8 & $\begin{array}{l}\text { Frequent SP breakdown, Impossible to aftercare services and } \\
\text { SP upgrade }\end{array}$ \\
\hline
\end{tabular}

Cl: cochlear implant

Table 2. Electrodes used in initial and revision $\mathrm{Cl}$ surgery

\begin{tabular}{|c|c|c|c|c|c|c|}
\hline \multirow[b]{2}{*}{ Patient No. } & \multicolumn{3}{|c|}{ 1st implant } & \multicolumn{3}{|c|}{ 2nd implant } \\
\hline & Array & Speech processor & $\begin{array}{c}\text { No. of active } \\
\text { electrode }\end{array}$ & Array & Speech processor & $\begin{array}{c}\text { No. of active } \\
\text { electrode }\end{array}$ \\
\hline 1 & $\mathrm{Cl} 22 \mathrm{M}$ & Spectra & na & $\mathrm{Cl} 422$ & Nucleus 6 & 24 \\
\hline 2 & $\mathrm{Cl} 22 \mathrm{M}$ & Spectra & na & $\mathrm{Cl} 512$ & Nucleus 5 & 11 \\
\hline 3 & $\mathrm{Cl} 22 \mathrm{M}$ & Spectra & na & $\mathrm{Cl} 422$ & Nucleus 6 & 24 \\
\hline 4 & $\mathrm{Cl} 24 \mathrm{M}$ & ESPrit22 & 22 & Cl24RE(ST) & Nucleus 5 & 24 \\
\hline 5 & $\mathrm{Cl}$ & PSP & 16 & Concerto & Rondo & 12 \\
\hline 6 & $\mathrm{Cl}$ & PSP & 16 & HiRes90K & Neptune & 16 \\
\hline 7 & $\mathrm{Cl}$ & PSP & 16 & HiRes90K & Neptune & 16 \\
\hline 8 & $\mathrm{Cl}$ & PSP & 16 & $\mathrm{Cl} 24 \mathrm{RE}(\mathrm{CA})$ & Freedom & 24 \\
\hline
\end{tabular}

Cl: cochlear implant 


\section{Results}

\section{CAP score}

We checked CAP score to compare auditory performance of total eight subjects between first and revision CI surgery. Mean CAP score after first CI surgery was $3.9 \pm 1.2$ and mean CAP score after revision CI surgery was $5.6 \pm 1.3$. The difference between initial surgery and revision surgery was statistically significant $(p=0.01)$. We have proved the statistic through Wilcoxon signed rank test. The change of CAP score before and after revision surgery in each case was demonstrated in Fig. 1.

\section{Vowel and consonant confusion test}

We evaluated ability to distinct vowel and consonant sound using the Seoul National University Hospital (SNUH)-confusion test in auditory only situations. The test consisted of nine 'h-vowel-d' sound and 18 'vowel-consonant-vowel' sound. Subjects heard the computerized pre-recorded test sounds and pointed the right example in auditory only situations. Mean vowel confusion test score was $60.5 \pm 39.4 \%$ after first CI surgery and $83.8 \pm 19.5 \%$ after revision surgery. The difference of two scores was significant statistically $(p=0.041)$. Mean consonant confusion test score was $36.5 \pm 27.8 \%$ after first CI surgery and $63 \pm 31.8 \%$ after revision surgery. This difference was not significant statistically $(p=0.063)$. The score of one case was worse rather than first surgery in the consonant confusion test. Fig. 2 and 3 displayed change of vowel and consonant confusion test score before and after revision surgery in each case. Case number 4 patient showed decreased score after revision surgery.

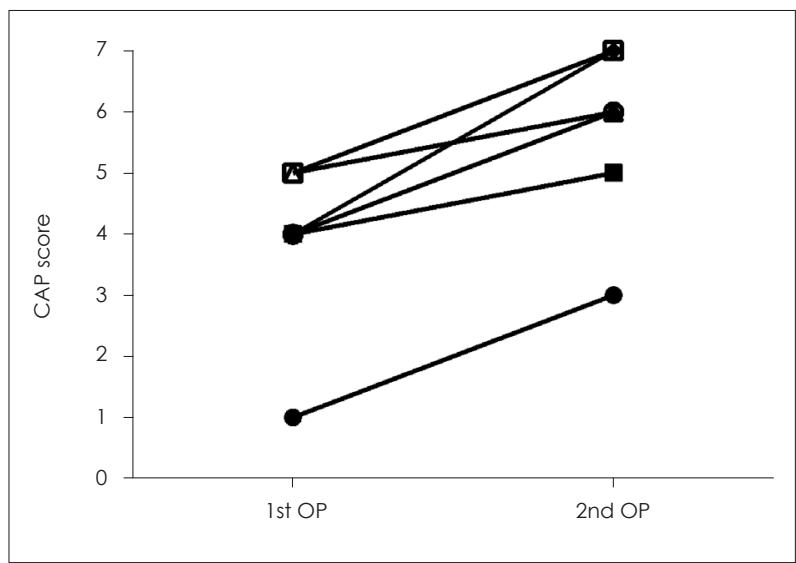

Fig. 1. Changes in CAP score of total eight subjects who underwent revision surgery. The mean value after the first operation was $3.9 \pm 1.2$ and the mean value after revision surgery was $5.6 \pm 1.3$. The difference of two scores was significant statistically $(p=0.01)$. CAP: Categories of Auditory Performance.

\section{Ling 6 sounds}

Average Ling 6 sounds test score after first CI surgery was $4.0 \pm 2.3$. After revision CI surgery, average Ling 6 sounds test score was $5.4 \pm 1.4$. The difference of the two results was not significant statistically $(p=0.066)$. One patient got worse in Ling 6 sound test after revision surgery. The change of Ling 6 sounds test before and after revision surgery in each case was demonstrated in Fig. 4. Case number 7 patient showed decreased score after revision surgery.

\section{Word identification test}

We used the Yoon's phonetically balanced test for monosyllabic word identification test and used the Dong-A University Hospital bisyllabic word list for bisyllabic word identification. After first CI surgery, mean score of monosyllabic word

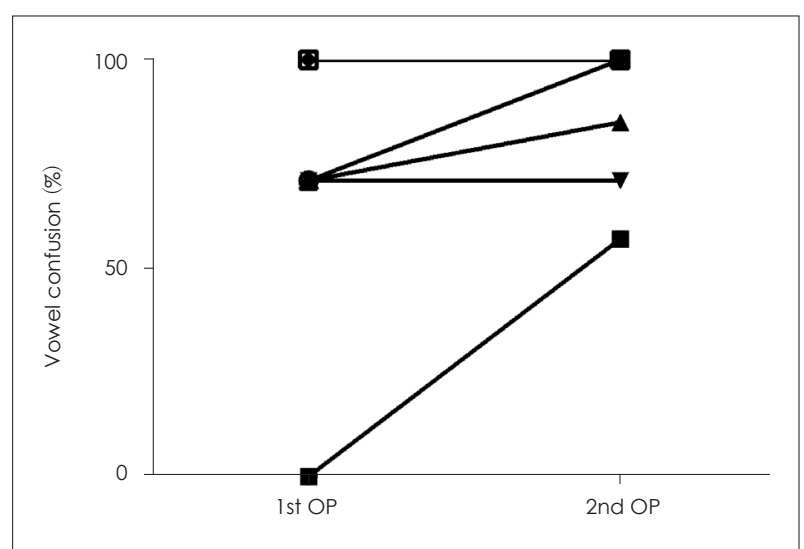

Fig. 2. Changes in vowel confusion test score of total eight subjects who underwent revision surgery. Mean vowel confusion test score was $60.5 \pm 39.4 \%$ after first $\mathrm{Cl}$ surgery and $83.8 \pm 19.5 \%$ after revision surgery. The difference of two scores was significant statistically ( $p=0.041)$. CAP: Categories of Auditory Performance, $\mathrm{Cl}$ : cochlear implant.

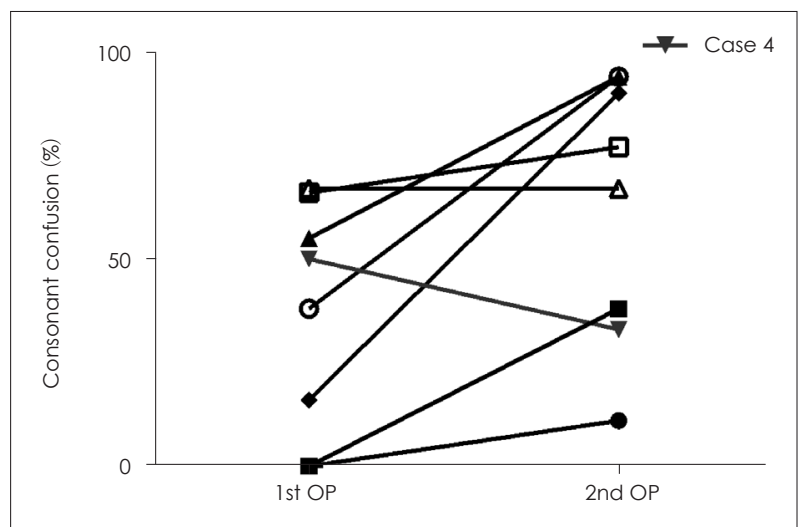

Fig. 3. Changes in score of consonant confusion test of total eight subjects who underwent revision surgery. Mean consonant confusion test score was $36.5 \pm 27.8 \%$ after first $\mathrm{Cl}$ surgery and $63 \pm 31.8 \%$ after revision surgery. This difference was not significant statistically $(p=0.063)$ and case number 4 patient showed decreased score after revision surgery. $\mathrm{Cl}$ : cochlear implant. 


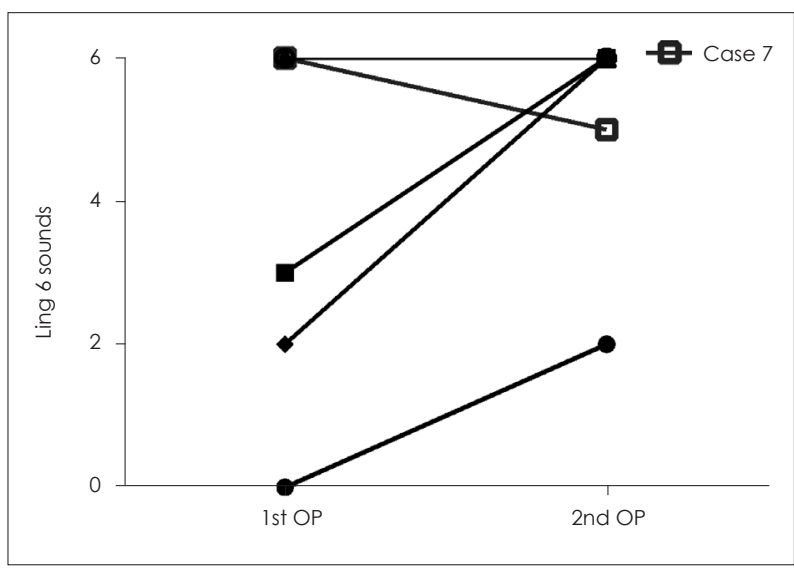

Fig. 4. Changes in Ling 6 sound test of total eight subjects before and after revision surgery. Average Ling 6 sound test score after first $\mathrm{Cl}$ surgery was $4 \pm 2.3$ and after revision $\mathrm{Cl}$ surgery, average Ling 6 sounds test score was $5.4 \pm 1.4$. The difference of the two results was not significant statistically $(p=0.066)$. Case number 7 patient showed decreased score after revision surgery. Cl: cochlear implant.

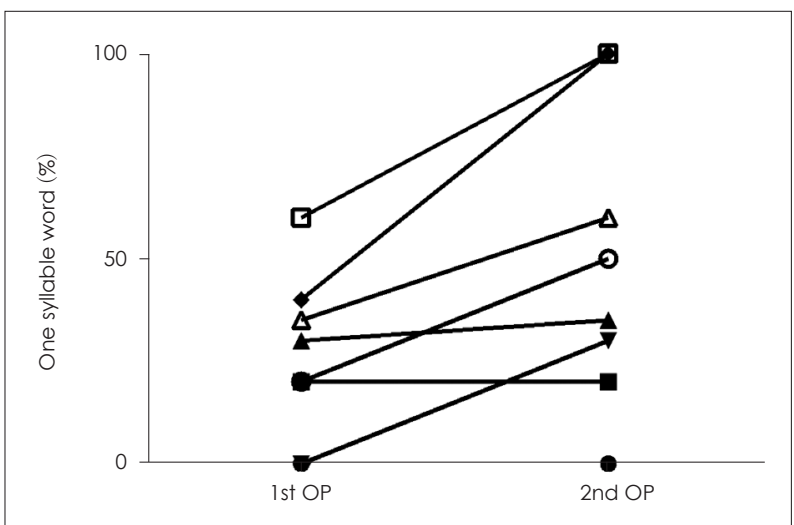

Fig. 5. Changes in one syllable word identification test of total eight subjects who underwent revision surgery in closed set situation. After first $\mathrm{Cl}$ surgery, mean score of monosyllabic word identification test was $25.6 \pm 20.3 \%$ and mean score after revision surgery was $49.4 \pm 36.1 \%$. This difference was meaningful statistically $(p=0.026)$. Cl: cochlear implant.

identification test was $25.6 \pm 20.3 \%$ and mean score after revision surgery was $49.4 \pm 36.1 \%$. This difference was meaningful statistically $(p=0.026)$. In bisyllabic word identification test, average score of bisyllabic word was $32.5 \pm 19.8 \%$ and average score after revision surgery was $56 \pm 34.7 \%$. This difference was statistically significant $(p=0.028$ ). All patients showed improvement in monosyllabic and bisyllabic word identification but two patients had no improvement in these tests. Fig. 5 and 6 showed change of word identification test before and after revision surgery in closed set situation. Case number 2 patient showed decreased result after revision surgery.

\section{Sentence identification test}

For ability of sentence identification, we used SNUH Sen-

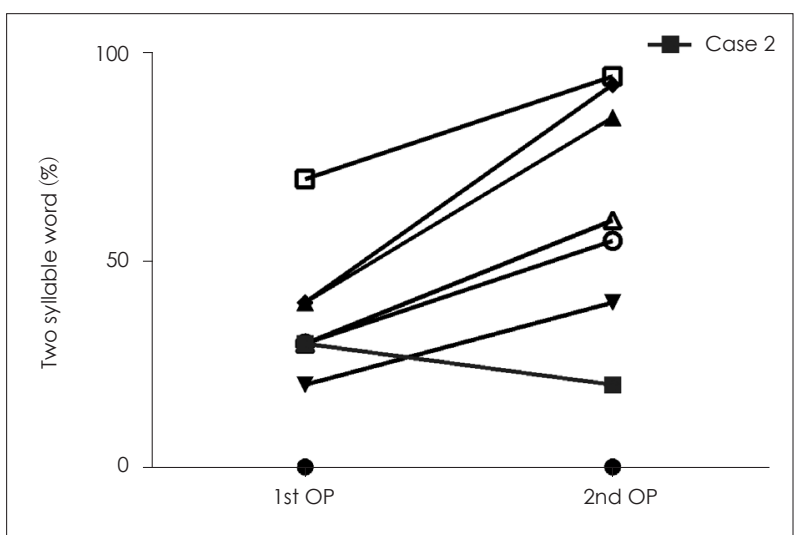

Fig. 6. Changes in two syllable word identification test of total eight subjects who underwent revision surgery in closed set situation. Average score was $32.5 \pm 19.8 \%$ and average score after revision surgery was $56 \pm 34.7 \%$. This difference was statistically significant $(p=0.028)$. Case number 2 patient showed decreased result after revision surgery.

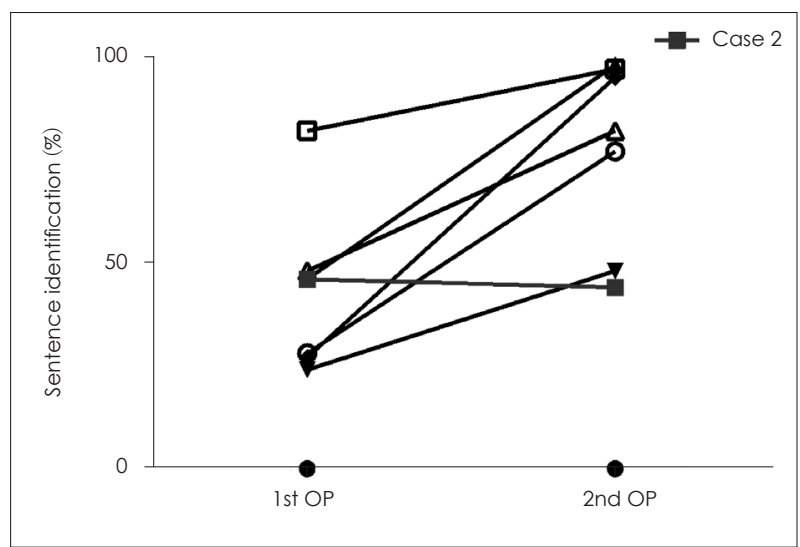

Fig. 7. Changes in sentence identification test of total eight subjects before and after revision surgery. Average score of sentence identification after first $\mathrm{Cl}$ surgery was $37.6 \pm 24.0 \%$ and $67.6 \pm 34.5 \%$ after revision $\mathrm{Cl}$ surgery. This difference of score was significant statistically $(p=0.028)$. Case number 2 patient showed a minimal decreased score after revision surgery. $\mathrm{Cl}$ : cochlear implant.

tence test: Korean-Central Institute for the Deaf (SNUH-SA: K-CID test). Average score of sentence identification after first CI surgery was $37.6 \pm 24.0 \%$ and $67.6 \pm 34.5 \%$ after revision CI surgery. This difference of score was significant statistically ( $p=0.028)$. Same as above paragraph, two patients had no improvement. Fig. 7 displayed change of sentence identification test before and after revision surgery in each case. Case number 2 patient showed a minimal decreased score after revision surgery.

The law data of all test results are summarized in Table 3.

\section{Discussion}

Currently, it is generally recognized that newer speech processors result in better performance. But in case of earlier CI 


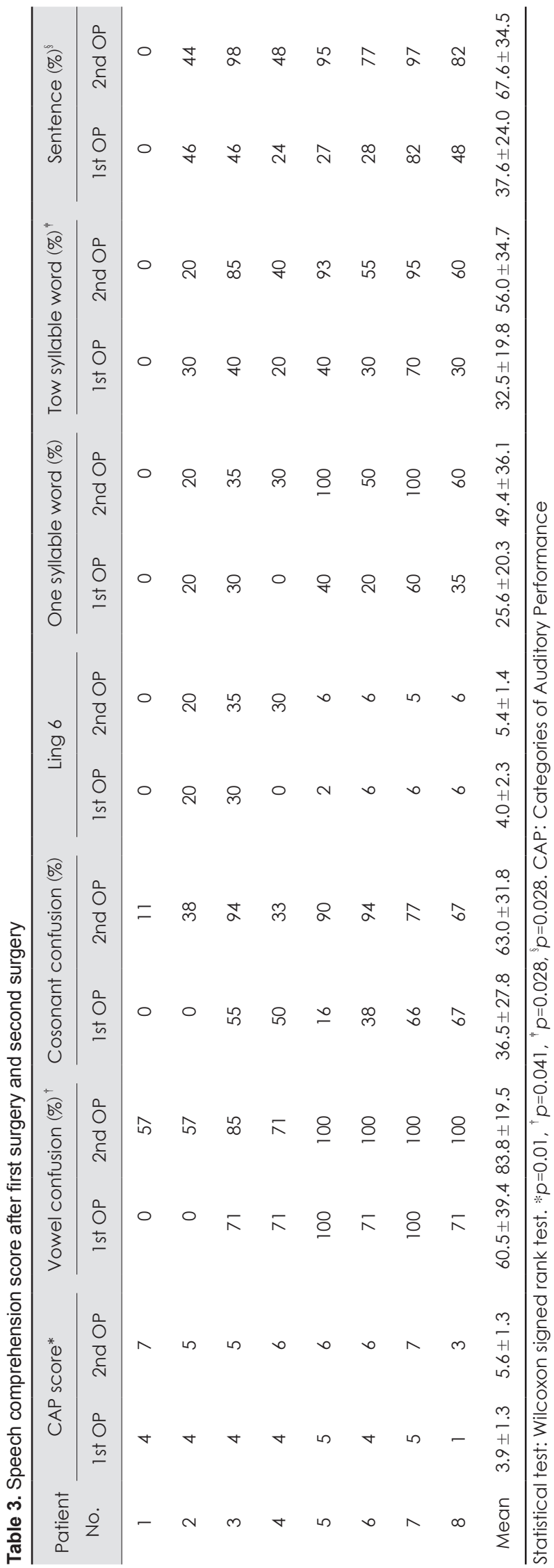

models it is impossible to upgrade speech processors. For example, in our cases, patient 1-3 were implanted with CI22M and patient 5-8 were implanted with Clarion 1.0 internal implant device, these implants cannot be upgraded to the newer CP810, CP910 or Neptune speech processor. We discussed this with patients, and decided to change the whole CI system. Patient 4 was implanted with a CI24M internal device. A CI24M implant can change to a newer speech processor CP810 or CP910, but because of frequent speech processor breakdown, patients wanted to change the whole system. We searched literature about performance of the whole system upgrade, but we could not find relevant literature. Practically the entire literature covers CI upgrade was studied with respect to speech processor upgrade. We cautiously announced to subjects about this point and made progress revision CI surgery. Fortunately, the patients were satisfied with their results. Their speech comprehension improved after revision surgery even if some of the speech tests were not significantly improved in each case.

Our study shows statistically significant improved results in speech comprehension tests after revision surgery except consonant confusion tests and Ling 6 sounds tests. In case of consonant confusion tests and Ling 6 sounds tests, even it is not significant statistically, most of patients experienced improved results. In three tests (consonant confusion test, Ling 6 sounds test, two syllable word identification test) of all seven speech comprehension tests, each patient's result was worse than it of after first CI surgery. Each was a different patient. We do not know why there were worse results. Each patient with worse test results had good test results for another test. We think these worse results are exceptional case problems.

Since the first report about possibility of revision CI surgery1, many researchers reported good results with revision CI surgery. Rivas, et al. [9] insisted that revision cochlear implantation can be safely performed to restore lost benefit in appropriately selected cases. They emphasized if properly performed after medical and audiologic options have been exhausted, revision CI surgery rarely compromises previous function and can resolve functional complaints and distracting symptoms. In case of young patients, Cullen, et al. [4], in their study of pediatric revision CI surgery, revealed that performance of after revision surgery is expected to equal or surpass the child's best level of performance before revision surgery. Olgun, et al. [6] reported experiences with 957 cases of pediatric $\mathrm{CI}$ revision surgery and reimplantation, their results were comparable with primary implantation. Chung, et al. [3] revealed restored speech performance of "soft failure (device malfunction is suspected but cannot be proven)" patients after revision CI surgery. Zeitler, et al. [10] reported that there is 
high rate of surgical success in revision CI surgery with preservation or improvement of pre-operative performance in most of the patients. They assert importance of thoughtful preparation, individualized patient counseling, and proper surgical technique for successful outcomes. Wang, et al. [11] reported their 30 years' experience with revision CI cases in adults and children; they reported $8.3 \%$ revision rate and $4.8 \%$ device failure rate. The most common indication for revision surgery was device failure (57.8\%), followed by migration/extrusion $(23.4 \%)$, infection/wound complication $(17.0 \%)$, and poor outcome/secondary pathology $(6.4 \%)$. So we expected better results with revision surgery using newer devices and proceeding with this study.

Compared to the past, there have been many improvements of the CI device. The number of electrodes has changed and coding strategy has been improved. Many previous studies have concluded that advanced concepts in CI improved speech comprehension. Lorens, et al. [12] evaluated the performance of a group of experienced children upgraded from the TEM$\mathrm{PO}+($ continuous interleaved sampling + coding strategy) to the newer OPUS 2 [fine structure processing coding strategy] speech processor. In their study, participants with the newer processor (OPUS 2) had better performance. They concluded that the old speech processor may be upgraded to a newer processor and new coding strategy doesn't compromise their listening performance but improves their performance [12]. Seebens and Diller [13] revealed similar result in their study about upgrading form TEMPO+ to OPUS 2 speech processor. In the long-term follow up study about upgrading to speech processor with newer coding strategy, subjects with newer speech processor revealed better performance [14]. As above mentioned, there is no documented analysis of the impact of the whole system upgrade on speech performance. We expect that this study will be useful for patients with the same conditions as those of this study.

Limitation of our study was that all subjects were of the hard or soft failure groups. Due to ethical and cost issues, we could not proceed with this study targeting patients without hard or soft failure completely. So interpretation about results of our study should be limited.

In conclusion, although there are some limitations in our study design, we could identify the effect of revision (upgrade)
CI surgery indirectly. So we concluded that if patients complain about low functional gain or low satisfaction after first CI surgery, revision (upgrade) CI surgery is meaningful even if there is no device failure.

\section{Acknowledgments}

This work was supported by the National Research Foundation of Korea (NRF) grant funded by the Korea government (MSIP) (2018R1 A2B6002952).

\section{Conflicts of interest}

The authors have no financial conflicts of interest.

\section{REFERENCES}

1) Hochmair-Desoyer I, Burian K. Reimplantation of a molded scala tympani electrode: impact on psychophysical and speech discrimination abilities. Ann Otol Rhinol Laryngol 1985;94(1 Pt 1):65-70.

2) Buchman CA, Higgins CA, Cullen R, Pillsbury HC. Revision cochlear implant surgery in adult patients with suspected device malfunction. Otol Neurotol 2004;25:504-10.

3) Chung D, Kim AH, Parisier S, Linstrom C, Alexiades G, Hoffman R, et al. Revision cochlear implant surgery in patients with suspected soft failures. Otol Neurotol 2010;31:1194-8.

4) Cullen RD, Fayad JN, Luxford WM, Buchman CA. Revision cochlear implant surgery in children. Otol Neurotol 2008;29:214-20.

5) Fayad JN, Baino T, Parisier SC. Revision cochlear implant surgery: causes and outcome. Otolaryngol Head Neck Surg 2004;131:429-32.

6) Olgun Y, Bayrak AF, Catli T, Ceylan ME, Aydin R, Duzenli U, et al. Pediatric cochlear implant revision surgery and reimplantation: an analysis of 957 cases. Int J Pediatr Otorhinolaryngol 2014;78:1642-7.

7) Rivas A, Wanna GB, Haynes DS. Revision cochlear implantation in children. Otolaryngol Clin North Am 2012;45:205-19.

8) Roland JT Jr, Huang TC, Cohen NL. Revision cochlear implantation. Otolaryngol Clin North Am 2006;39:833-9.

9) Rivas A, Marlowe AL, Chinnici JE, Niparko JK, Francis HW. Revision cochlear implantation surgery in adults: indications and results. Otol Neurotol 2008;29:639-48.

10) Zeitler DM, Budenz CL, Roland JT Jr. Revision cochlear implantation. Curr Opin Otolaryngol Head Neck Surg 2009;17:334-8.

11) Wang JT, Wang AY, Psarros C, Da Cruz M. Rates of revision and device failure in cochlear implant surgery: a 30-year experience. Laryngoscope 2014;124:2393-9.

12) Lorens A, Zgoda M, Obrycka A, Skarżynski H. Fine Structure Processing improves speech perception as well as objective and subjective benefits in pediatric MED-EL COMBI 40+ users. Int J Pediatr Otorhinolaryngol 2010;74:1372-8.

13) Seebens Y, Diller G. Improvements in speech perception after the upgrade from the TEMPO+ to the OPUS 2 audio processor. ORL J Otorhinolaryngol Relat Spec 2012;74:6-11.

14) Kleine Punte A, De Bodt M, Van de Heyning P. Long-term improvement of speech perception with the fine structure processing coding strategy in cochlear implants. ORL J Otorhinolaryngol Relat Spec 2014;76:36-43. 